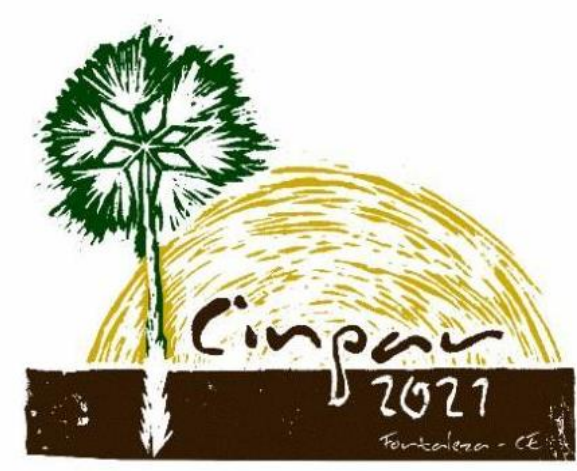

XVII Congresso Internacional sobre Patologia e

Reabilitação das Construções

XVII Congreso Internacional sobre Patología y Rehabilitación de las Construcciones

XVII International Conference on Pathology and Constructions Rehabilitation

FORTALEZA (Brasil), 3 a 5 de junho de 2021

https://doi.org/10.4322/CINPAR.2021.065

\title{
Anamnese e gestão de reabilitação em patrimônio: Estudo de caso do patrimônio histórico do município de Curvelo/MG
}

\section{Anamnesis and management of heritage rehabilitation: Case study of historical heritage of the municipality of Curvelo/MG}

Jéssica Lourenço Brandão SILVA ${ }^{1}$, Nicole Aparecida de Macedo SOUZA ${ }^{2}$, Marcos de Paulo RAMOS ${ }^{3}$, Thiago Pena BORTONE ${ }^{4}$, Rachel Jardim MARTINI ${ }^{5}$

\footnotetext{
${ }^{1}$ CEFET/MG, Curvelo, Brasil, jessicalourenco3405@gmail.com

${ }^{2}$ CEFET/MG, Curvelo, Brasil, nicolemacedo679@gmail.com

${ }^{3}$ CEFET/MG, Curvelo, Brasil, marcos.ramos@cefetmg

${ }^{4}$ CEFET/MG, Curvelo, Brasil, thiago.bortone@cefetmg.br

${ }^{5}$ CEFET/MG, Curvelo, Brasil, martini@cefetmg.br
}

\begin{abstract}
Resumo: Nos últimos trinta anos, o patrimônio histórico tem despertado o interesse da comunidade científica para o desenvolvimento de estratégias e metodologias de suporte à gestão de reabilitação. As manifestações patológicas, anomalias ou falhas construtivas, são caracterizadas pela ocorrência de problemas, falhas ou defeitos que prejudicam o edifício em vários aspectos, tanto estruturais quanto estéticos. O objetivo principal deste artigo é apresentar a importância da anamnese e da gestão de reabilitação de edificações como suporte a preservação dos patrimônios históricos, além de destacar que irregularidades de manutenções passadas podem apresentar consequências para a situação atual destes patrimônios construídos. A partir de um estudo de caso no Prédio Lúcio Cardoso, conhecido como Prédio 2, pertencente ao conjunto urbano da Praça Central do Brasil no Município de Curvelo/MG, foi possível analisar estas consequências. Esse artigo mostrou, por meio da anamnese, o histórico da mesma, as técnicas construtivas retrospectivas, os materiais usados nessas construções históricas e sua situação atual de preservação. Dessa forma, foi possível classificar as anomalias encontradas, estimar a idade do patrimônio, compreender suas alterações de uso, intervenções, reformas, entre outras informações. Para o patrimônio em estudo, preservado até os dias atuais, foram apontadas as causas dessas anomalias e verificadas se ocorreram por manutenções inadequadas. A metodologia utilizada aborda uma revisão bibliográfica sobre as anomalias presentes, com uma compilação de documentos e uma análise comparativa dos laudos de vistorias existentes, que são obrigatórios para o processo de tombamento do patrimônio. Com este trabalho, foi possível relacionar as manifestações patológicas identificadas com possíveis falhas de uso, operação ou manutenção. Por fim, cabe ressaltar a importância de se preservar os patrimônios históricos com a gestão de reabilitação, a fim de que essas informações possam ser usadas e atualizadas nos processos de conservação e reabilitação do patrimônio construído.
\end{abstract}

Palavras-chave: Anomalia, anamnese, gestão patrimonial e manifestações patológicas.

Abstract: In the last thirty years, the historical heritage has aroused the interest of the scientific community for the development of strategies and methodologies to support rehabilitation management. Pathological manifestations, anomalies or construction failures are characterized by the occurrence of problems, failures or defects that damage the building in various aspects, both structural and aesthetic. The main objective of 
this work is to present the importance of anamnesis and management of the rehabilitation of buildings as a support for the preservation of historical heritage, in addition to highlighting the fact that irregularities in past maintenance may have consequences for the current situation of these built heritage. Based on a case study at the Lúcio Cardoso Building, known as Building 2, belonging to the urban complex of Praça Central do Brasil in the Municipality of Curvelo/MG, it was possible to analyze these consequences. This work showed, through the anamnesis, its history, the retrospective construction techniques, the materials used in these historical constructions and its current preservation situation. Thus, it was possible to classify the anomalies found, estimate the age of the heritage, understand its changes in use, interventions, reforms, among other information. For the heritage under study, preserved until the present day, the causes of these anomalies were identified and verified if they occurred due to inadequate maintenance. The methodology used addresses a bibliographic review on the anomalies present, with a compilation of documents and a comparative analysis of the existing inspection reports, which are mandatory for the heritage listing process. With this work, it was possible to relate the pathological manifestations identified with possible failures in use, operation or maintenance. Finally, it is worth emphasizing the importance of preserving historical heritage with the management of rehabilitation, so that this information can be used and updated in the processes of conservation and rehabilitation of the built heritage.

Keywords: Anomaly, anamnesis, management of heritage and pathological manifestations.

\section{Introdução}

O estudo da anamnese, de acordo com a norma ABNT NBR 16747:2020 - Inspeção predial, é uma etapa que consiste em uma ou mais entrevistas para a coleta de dados e obtenção de informações sobre o histórico da edificação, além de reunir estudos documentais, cartográficos, investigação in loco e análise de especialistas na área (ABNT, 2020). Com essa investigação é possível propor formas de diminuir a reincidência das manifestações patológicas em patrimônios e evitar sua degradação.

A gestão de reabilitação em patrimônios tem como papel fundamental garantir a integração entre os especialistas ao longo de toda a vida útil do edificado. Esta gestão deve ser realizada com envolvimento de diversos setores da sociedade, e nesse contexto vale ressaltar a criação do programa PAC (Programa de Aceleração do Crescimento) Cidades Históricas. Este programa surgiu em 2013 e tem a sociedade como participante nos planos de ação de proteção e reabilitação do edificado (IPHAN, 2014).

Este artigo visou demonstrar como as condições de uso, operação, manutenção e funcionalidade das edificações históricas podem estar relacionadas às incidências de manifestações patológicas. As vistorias frequentes, manutenções preventivas e corretivas com profissionais qualificados e uso de materiais de boa qualidade podem contribuir na proteção e reabilitação dos patrimônios históricos. A incidência de manifestações patológicas neste tipo de edificação acaba por causar uma diminuição de seu desempenho e também afeta negativamente a estética arquitetônica da estrutura. Além disso, estes problemas podem comprometer a segurança estrutural do edificado e pôr em risco o bem patrimonial. De maneira geral, as manifestações patológicas das edificações tendem a intensificar-se com o tempo, e se não forem rapidamente e corretamente tratadas, podem causar inúmeros danos, e nos casos mais graves, contribuir para o colapso da estrutura (BRAGA, 2019).

O Município de Curvelo/MG foi escolhido para a realização do estudo de caso por apresentar diversas estruturas históricas, arquitetônicas e urbanísticas. A Prefeitura Municipal tem listado estes bens culturais, tombados e inventariados, desde edificações de pequeno e médio porte até Igrejas, Capelas e a famosa Estação Ferroviária da Cidade. Além disso, desde 2014, com a criação da Lei $n^{\circ}$ 2895/2014, a cidade reestruturou a política municipal de proteção ao patrimônio, o que proporcionou maior proteção a estes bens (CURVELO, 2014).

Neste trabalho é apresentada uma breve descrição sobre como eram as construções curvelanas no passado e suas mudanças desde os primórdios da Construção Civil até o século atual. As formas de se ver os papéis dos responsáveis pela obra, os materiais utilizados e, principalmente, as técnicas construtivas, que consequentemente interferem no surgimento de diversos tipos de anomalias, evoluíram ao longo do tempo. 
Para auxiliar na classificação das anomalias identificadas, este trabalho optou pelo uso da matriz GUT (Gravidade, Urgência e Tendência). De acordo com Braga (2019), no método GUT, a Gravidade (G) representa a importância do problema a ser examinado e seu potencial de dano. Geralmente seu estudo é realizado visando efeitos a médio e longo prazos; a Urgência (U) exige a análise de quão significativo é o problema, ou seja, o prazo para a realização do feito; e a Tendência (T) consiste na evolução do problema em função do tempo.

\section{Metodologia}

A reabilitação de patrimônios edificados exige uma organização de estudos e análises. Anamnese, diagnóstico, terapia e controle correspondem, respectivamente, à análise da informação histórica, identificação das causas das degradações, seleção das ações de reabilitação e controle da eficácia das intervenções. Para assegurar a eficiência deste processo, pode ser necessário repetir essa fase num processo iterativo (ICOMOS, 2002).

O estudo baseou-se em uma estratégia histórica, que compreende o estudo da concepção da edificação, sua funcionalidade, as técnicas e a mão-de-obra utilizadas na sua execução, as alterações posteriores (tanto na estrutura como na envolvente) e quaisquer ocorrências que possam ter causado danos ao edificado. 0 objetivo é identificar as causas de determinadas manifestações patológicas identificadas, que podem ter decorrido de maus cuidados dos órgãos responsáveis (ICOMOS, 2002).

Nesta seção foi abordada a metodologia para a escolha do patrimônio a ser estudado, o histórico da edificação, o levantamento e coleta de dados por meio da anamnese do edificado e a classificação das anomalias constatadas através da matriz GUT. A seguir, foram propostas soluções para as anomalias identificadas.

O objetivo foi investigar como algumas das manifestações patológicas identificadas no Prédio 2, estudo de caso que é detalhado a seguir, tem relação com as irregularidades de manutenções passadas ou até mesmo a ausência destas. Para isso, foi realizada a anamnese com a coleta de dados de forma direta e indireta, que se refere a entrevista, vistoria e pesquisa documental acerca do imóvel.

O critério utilizado para escolha do estudo de caso foram as condições de logística, devido ao fácil acesso para a realização da vistoria do patrimônio, e pesquisa documental, pela disponibilização de dados e documentação fotográfica, obtidos junto à Prefeitura Municipal de Curvelo/MG.

A coleta de dados junto à Prefeitura Municipal de Curvelo/MG teve como foco a busca sobre as técnicas construtivas retrospectivas e materiais aplicados no patrimônio histórico em questão. Além disso, é apresentado um histórico sobre as anomalias encontradas no edificado e a documentação fotográfica.

Com os dados coletados, foi possível analisar as principais características construtivas para compreender o seu estilo e estrutura arquitetônica, os materiais utilizados na época da sua construção e as técnicas construtivas utilizadas. Também foi feito uma análise dos laudos de reformas no patrimônio para se ter um histórico da frequência e incidência das anomalias.

\section{Estudo de caso}

O estudo de caso é o Prédio Lúcio Cardoso, nomeado como Prédio 2, pertencente ao conjunto urbano da Praça Central do Brasil, situado à Avenida Integração, 141. Este edificado foi construído na mesma época da estação ferroviária e tombado no dia 29 de novembro de 2002 (CURVELO, 2003).

\subsection{Histórico da edificação}

O prédio era utilizado para abrigar trabalhadores em serviço na Antiga Estação Ferroviária, em meados de 1904. De acordo com Curvelo (2003), seu estilo é eclético, com detalhes em relevo, frisos, ornamentos, frontão trabalhado e pilares ressaltados, constituídos por base e capitel. Na época do tombamento, o Prédio 2 estava inserido em um terreno plano de grandes dimensões e imediatamente à frente deste existia um passeio estreito e sem pavimentação. A construção encontrava-se pouco recuada em relação ao alinhamento do terreno, não possuindo nenhum muro divisório, apenas uma cerca com esteios de madeira e arame. Trata-se de uma construção térrea, com volumetria simples, de apenas um pavimento, com 
planta em partido retangular. Após o processo de liquidação da REDE FERROVIÁRIA FEDERAL SOCIEDADE ANÔNIMA (R.F.F.S.A) e a consequente alienação de seus bens, a Prefeitura adquiriu este imóvel e as áreas adjacentes, objetivando dar continuidade ao processo de desenvolvimento histórico-cultural de Curvelo/MG e preservar a propriedade já tombada pelo Município (CURVELO, 2003). Na Figura 1, temos a planta do perímetro de entorno que mostra a localização do Prédio 2 assim como os demais prédios pertencentes ao conjunto urbano da Praça da Estação.

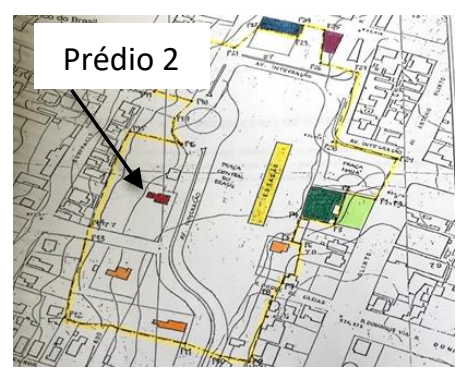

Figura 1 - Planta do perímetro de entorno.

Fonte: Curvelo, 2003.

\subsection{Anamnese do Patrimônio}

Foi realizada a anamnese do patrimônio para a identificação de suas características construtivas, materiais utilizados na sua construção, histórico de reformas, de vistorias e alterações de uso. De acordo com Curvelo (2003), a primeira vistoria no Prédio 2 foi realizada em 2002. Nessa vistoria, foi verificada que a estrutura, em alvenaria de tijolos maciços de barro, estava em bom estado de conservação, e que a sua alvenaria havia necessidade de reparação em alguns pontos.

De acordo com Medeiros (2017), no caso de patrimônios históricos, a idade das construções nos leva a uma falta de conhecimento sobre processos construtivos e sobre os materiais utilizados nas construções, o que acaba sendo um fator agravante no diagnóstico das manifestações patológicas. A parede da edificação é de tijolo maciço de barro, que na construção de edifícios antigos é conhecido como "burro", tinha em média as dimensões de 0,23 x 0,11 x 0,07m e as juntas não excediam 0,01 m de espessura (VEADO, 2008). Quanto ao revestimento das paredes, elas são argamassadas. Antigamente usava-se a terra como a matéria-prima básica constituinte da argamassa empregada na construção de prédios antigos.

$\mathrm{O}$ telhado era composto por telhas francesas dividido em duas águas e com a sua estrutura em madeira. $\mathrm{Na}$ vistoria realizada em 2002, algumas peças do telhado (ripas, caibros e telhas) apresentavam danos que demandavam reparos. $O$ forro, também em madeira, se apresentava à época, totalmente corrompido por animais xilófagos como cupins. As esquadrias eram de madeira maciça e estavam danificadas, assim como os vidros (CURVELO, 2003).

$\mathrm{Na}$ edificação, as janelas são retangulares e possuíam parte em vidro e folhas em venezianas. Em 2002, a porta de entrada encontrava-se com a madeira comprometida e é composta por duas folhas de abrir e detalhes almofadados (Figura 2(a)).

Na parte externa do edificado, o revestimento em seu reboco havia pontos danificados, a caiação estava gasta e queimada e seus elementos artísticos necessitavam de recomposição em parte. $O$ piso cimentado se encontrava com trincas e abatimentos, além do piso de madeira estar totalmente danificado. Na parte externa, a escada em piso cimentado estava em bom estado, a cercadura de fechamento do terreno com esteios e o arame farpado estava em péssimo estado, além do quintal em chão batido que precisava de uma limpeza (CURVELO, 2003).

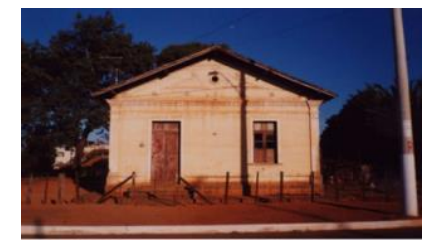

(a)

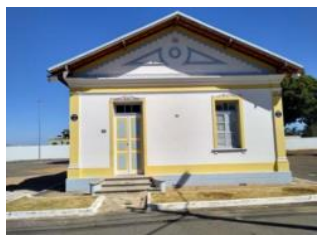

(b)

Figura 2 - (a) Fachada antiga da edificação (Fonte: Curvelo, 2003) e (b) Fachada atual da edificação 
Em 2020, a Secretaria Municipal de Cultura permitiu a inspeção do Prédio 2. Em vistoria realizada pelos autores, foi possível coletar diversas informações acerca da situação atual do edificado, que se encontra em reforma e, por este motivo, sem uso. Seu estado de conservação atual da fachada do imóvel é apresentado na Figura 2 (b), a calçada encontra-se irregular com alguns defeitos, escada sem corrimão e não possui rampas para a entrada de cadeirantes, a iluminação externa está em bom estado, com aparelhamento novo e refletores (sem iluminação autônoma).

A estrutura em alvenaria aparenta estar em bom estado. As paredes argamassadas possuem fissuras em encontros da alvenaria e destacamento no acabamento. Todas as paredes internas precisam de pintura após a reforma, mas a pintura externa está em bom estado.

As esquadrias são de madeira, a parte interna de todas as janelas da edificação sofreram ataque de pragas e a externa estavam em boas condições. Os trincos das janelas possuem uma perda de mobilidade ou deficiência na fechadura, com excesso de tinta nos trincos, alguns componentes das esquadrias da sala e cozinha estão danificados e parte das esquadrias foram arrancadas.

O sistema elétrico está em bom estado, porém, o quadro de distribuição se encontra aberto, os disjuntores estão expostos fora do quadro e existem cabos elétricos aparentes. Na parte externa, o padrão de energia está sem o vidro de proteção, o hidrômetro não possui a proteção adequada e a caixa de gordura sem tampa.

\subsection{Análise das manifestações patológicas encontradas}

Neste trabalho foram descritas as anomalias encontradas no estudo de caso, sendo estas: fissuras nas alvenarias, destacamento, umidades e anomalias nas peças de madeira. As fissuras podem surgir no decorrer da obra ou depois da obra concluída. Essa manifestação patológica é um dos tipos mais comuns de ser encontrada nas edificações e podem interferir na estrutura (se for mais grave), na estética, na durabilidade do imóvel e causar uma certa preocupação no usuário, pois a fissura é o primeiro indício para o aparecimento de anomalias mais graves.

As fissuras podem ocorrer de forma ativa ou passiva. As ativas são subdivididas em sazonais ou progressivas. As sazonais são caracterizadas por suas variações sensíveis de abertura e fechamento da fissura devido às diferenças de temperaturas. A progressiva pode aumentar de tamanho no decorrer do tempo, sendo estas perigosas para a vida útil da edificação (ANDRADE, 2020). Já as fissuras mapeadas, têm formas variadas e distribuem-se por toda superfície e sua causa é decorrente da retração da argamassa de base (LANNES, 2011).

Segundo Lima (2015), algumas das possíveis causas das fissuras nas obras são sintetizadas da seguinte maneira: avaliação incorreta das cargas atuantes, insuficiente resistência do material, excessiva deformidade do material utilizado, excesso de esbeltez na seção da peça, excentricidade da carga atuante. Trata-se de uma manifestação patológica crítica, sobretudo, quando se trata de revestimento em fachadas, tanto pelo risco de acidentes aos transeuntes quanto pela desvalorização do empreendimento e pelo comprometimento das funções de proteção e estanqueidade do edifício.

Segundo Brito (2014), ao se analisar uma estrutura "doente" é absolutamente necessário entender-se o porquê do surgimento e do desenvolvimento da manifestação patológica, buscando esclarecer as causas, antes da prescrição e consequente aplicação do remédio necessário.

O apodrecimento da madeira é a decomposição da madeira, mais comum pela ação de fungos, geralmente mofo ou bolor. A madeira é uma combinação de polímeros naturais que apresenta resistência e durabilidade como material estrutural. $O$ dano neste material pode variar desde pequenas descolorações causadas por fungos manchadores ou substâncias químicas até deteriorações mais graves por ataques de insetos e/ou fungos apodrecedores (BRITO, 2014).

Na Figura 3 (a) tem-se uma fissura de $1 \mathrm{~cm}$ da calçada, nesta não foi possível identificar sua causa ou algum eventual perigo estrutural. Na Figura 3 (b) tem-se uma fissura no encontro da alvenaria, os prováveis fatores dessa anomalia podem ser as condições climáticas, ações do tempo, envelhecimento dos materiais, falta de manutenção ou intervenções passadas realizadas com emprego de materiais incompatíveis. Também identifica-se manchas de umidade no piso do banheiro, representado na Figura 3 (c), causado possivelmente por vazamentos nas instalações hidráulicas do banheiro. $O$ ataque de pragas nas peças de 
madeira são visto nas Figura 3 (d) e Figura 3 (e) que possuem a presença da manifestação patológica nas madeiras das esquadrias, com o ataque de pragas (ex: fungos) perfurando a madeira, apodrecendo e enfraquecendo.

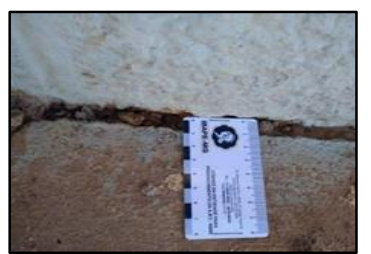

(a)

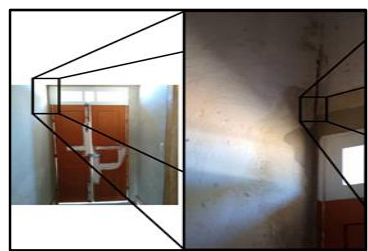

(b)

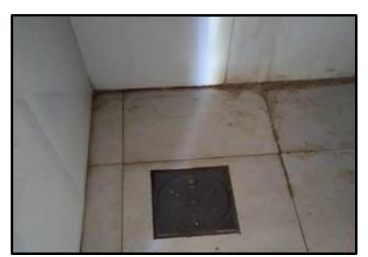

(c)

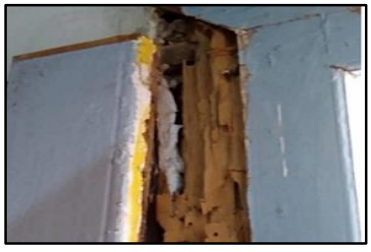

(d)

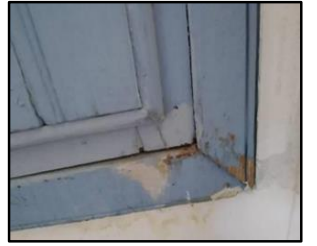

(e)

Figura 3 - Manifestações patológicas encontradas no prédio 2 em 2020, fissuras (a) e (b), umidade no piso (c) e esquadrias danificadas (d) e (e). Fonte: Acervo municipal da Secretaria de cultura de Curvelo/MG

\subsection{Soluções propostas}

\subsection{1 - Fissuras}

Segundo Muci (2014), a prevenção de fissuras em alvenarias de edifícios deve, obrigatoriamente, passar por todas as regras de planejar, projetar e construir, além de um controle sistemático e eficiente da qualidade dos materiais e dos serviços. A estocagem e o manuseio corretos dos materiais e componentes do canteiro de obras, o uso adequado do edifício, bem como uma boa manutenção, dentre outros fatores, não podem ser esquecidos.

A fissura no encontro da alvenaria tem localização próximo a porta, como mostra a Figura 3 (b), em seu entorno parece estar com uma certa umidade e a fissura se estende apenas no ponto da alvenaria. Essa é uma fissura geométrica (vertical nesse caso), caracterizada por ser uma manifestação patológica funcional, ou seja, seu surgimento se deu ao longo dos anos sem um reparo contínuo para preservar o patrimônio e sua possível causa é decorrente da expansão da argamassa de assentamento por hidratação retardada do óxido de magnésio da cal. Procedimentos de reparo para essa fissura, segundo VEADO (2008) são: eliminação da infiltração e umidade; substituição das camadas de revestimentos; renovação do revestimento após hidratação completa da cal da argamassa de assentamento; especificação a adotar é em função da intensidade da reação dos constituintes expansivos; renovação da pintura após a completa cura dos revestimentos.

\subsection{2 - Vazamento (Manchas de Umidade)}

As manchas de umidade mostrada na Figura 3 (c), caracteriza-se por ser oriunda de falhas nos sistemas de tubulações, como águas pluviais, esgoto e água potável, e acaba por gerar infiltrações. A existência de umidade com esse tipo de origem adquire importância especial quando se trata de edificações que já possuem um longo período de existência. Tal fato decorre da presença de materiais que podem ter seu tempo de vida já excedido, como sistemas de impermeabilizações e tubulações (dutos de ferro fundido para água potável ou manilhas cerâmicas para águas servidas), que não costumam ser contempladas em planos de manutenção predial (LERSCH, 2003).

\subsection{3 - Tratamento da madeira}

De acordo com Rodrigues (2013), os agentes biológicos são a causa mais frequente de deterioração das estruturas de madeira. Observando a degradação da madeira nas partes constituintes das esquadrias e das 
portas, conforme mostra as Figura 3 (d) e Figura 3 (e), identifica-se que houve um ataque de pragas que resultou na deterioração da estrutura em madeira. Devido a idade da estrutura e a ausência de reparos contínuos para a preservação, a madeira se degradou com o passar do tempo e fatores como umidade e falta de ventilação com a edificação fechada, propiciou o ataque de pragas.

\section{Discussão de resultados}

Como indicado previamente, as etapas de análise deste estudo foram feitas a partir de uma estratégia histórica, onde foram observadas as técnicas construtivas de um patrimônio histórico do Município de Curvelo/MG com o intuito de posteriormente se catalogar possíveis anomalias.

$\mathrm{Na}$ área total amostrada do patrimônio foram encontradas as seguintes anomalias: fissuras em alvenarias, manchas de umidade, destacamento e manifestações patológicas em madeira. Para classificá-los de acordo com a matriz GUT, utilizou-se de análise fotográfica das manifestações patológicas encontradas no estudo de caso do Prédio 2. Com isso, registrou-se os níveis de Gravidade, Urgência e Tendência para cada uma delas, sendo de 1 (menos grave) a 5 (mais grave), conforme mostra o quadro $1 \mathrm{com}$ os resultados das análises.

Quadro 1 - Matriz de prioridades GUT (gravidade, urgência e tendência)

\begin{tabular}{|c|c|c|c|c|c|}
\hline \multicolumn{7}{|c|}{ Matriz de Prioridades GxUxT } \\
\hline Problema & Gravidade & Urgência & Tendência & GxUxT & Classificação \\
\hline Fissuras & 4 & 3 & 5 & 60 & 10 \\
\hline $\begin{array}{c}\text { Umidade } \\
\text { acidental }\end{array}$ & 3 & 2 & 4 & 24 & 20 \\
\hline $\begin{array}{c}\text { Patologias em } \\
\text { madeira }\end{array}$ & 3 & 3 & 2 & 8 & 3ㅇ \\
\hline Destacamento & 2 & 1 & 2 & 4 & 4ㅇ \\
\hline
\end{tabular}

\section{Conclusão}

Após a realização da anamnese do Prédio 2 foi possível conhecer o histórico da edificação e entender melhor suas técnicas construtivas e identificar anomalias possivelmente causadas pelas mesmas. A vistoria realizada pelos autores contribuiu para a análise das manifestações patológicas atuais. Para esta edificação foram encontradas manifestações patológicas como: fissuras, destacamento, degradação da madeira e manchas de umidade. A anamnese melhorou a compreensão e identificação dos diversos aspectos da edificação através da análise dos relatórios fotográficos pretéritos e atual, com registros entre os anos de 2002 e 2020. Esta avaliação histórica contribuiu na identificação das mudanças estéticas, construtivas e a evolução ou permanência das manifestações patológicas ao longo dos anos. Para cada uma das principais anomalias encontradas no estudo de caso em questão, foram apresentadas possíveis soluções e com auxílio da matriz GUT foi possível classificá-las e definir qual anomalia mais comprometeu o edificado.

A discussão dos resultados trouxe que as fissuras, manchas de umidade e as manifestações patológicas em madeiras (abaulamentos, ataque de animais xilófagos, entre outros), ficaram em primeiro, segundo e terceiro lugar, respectivamente, em caráter de Gravidade, Urgência e Tendência. Assim dar-se-á entender que os reparos dessas manifestações patológicas são de suma importância para a reabilitação desse prédio, enquanto que para o destacamento da pintura não há urgência de ser tratado, pois o edificado em estudo está em reforma atualmente. Destacou-se a importância da anamnese e da gestão de reabilitação em patrimônio como suporte a preservação dos patrimônios históricos, pois assim foi possível destacar algumas irregularidades de manutenções passadas e suas consequências para a situação atual desse patrimônio construído. Esse trabalho obteve uma base de dados acerca do assunto de gestão patrimonial e manifestações patológicas em patrimônios históricos, o que pode auxiliar futuros pesquisadores a se aprofundarem nesse assunto importante no campo da edificação histórica. A preservação e reabilitação desses patrimônios históricos, salvam sua história, preservam suas memórias para a sua comunidade e evita-se a deterioração dos edificados, enaltecendo a sustentabilidade dessas edificações, as vezes esquecidas, e que devem ser mais valorizadas culturalmente. 


\section{Agradecimentos}

Agradecemos ao Centro Federal de Educação Tecnológica de Minas Gerais - CEFET-MG pelo apoio direto e indireto a este trabalho e também a Prefeitura Municipal de Curvelo/MG por permitirem a realização deste estudo e por se colocarem à disposição para auxiliar em qualquer questão necessária. Também agradecemos ao apoio do LAR - Laboratório de Avaliação e Reabilitação de Ambiente Construído do CEFETMG - Campus Curvelo e ao Programa de Pós-graduação de Engenharia Civil do Campus II - Belo Horizonte, bem como a equipe do Projeto de Pesquisa PIBIC-Jr "Caracterização e avaliação do patrimônio histórico da região de Curvelo" pelo incentivo a este trabalho.

\section{Referências Bibliográficas}

ABNT, Associação brasileira de normas técnicas. NBR 16747 - Inspeção predial, 2020.

ANDRADE, Erika B. B. Principais manifestações patológicas encontradas em edificação. 2020. Disponível em: https://m.monografias.brasilescola.uol.com.br/engenharia/principais-manifestacoes-patologicasencontradas-em-uma-edificacao.htm\#indice_18 Acesso em: setembro de 2020

BRAGA, I. C., Brandão, F. S., Ribeiro, F. R. C., Diógenes, A. G. (2019), "Aplicação da Matriz GUT na análise de manifestações patológicas em construções históricas", Revista ALCONPAT, 9(3), pp. 320 - 335, DOI: http://dx.doi.org/10.21041/ra.v9i3.400.

BRITO, Leandro D. Patologia em estruturas de madeira: metodologia de inspeção e técnicas de reabilitação. 2014. 502 f. Tese (Doutorado) - Programa de Pós-Graduação em Engenharia de Estruturas Universidade de São Paulo, 2014.

Curvelo, Prefeitura Municipal de. Dossiê de tombamento de 2002 - Prédio 2, Curvelo, 2003.

Curvelo, Prefeitura Municipal de. LEI № 2.895, DE 15 DE DEZEMBRO DE 2014. Curvelo, MG, 2014.

ICOMOS - Recomendações para a Análise, Conservação e Restauro Estrutural do Património Arquitectónico, Lisboa, Junho, 2002. Disponível em: https://core.ac.uk/download/pdf/55604452.pdf Acesso em: setembro de 2020.

IPHAN, 2014. Disponível em: http://portal.iphan.gov.br/ Acesso em: fevereiro de 2021.

LANNES, Liege Dias. Reincidência de danos em prédio histórico preservado. 2011. 277f. Dissertação (Mestrado) - Programa de Pós-Graduação em Arquitetura e Urbanismo. Universidade Federal de Pelotas, Pelotas.

Lersch, I. M. (2003) "Contribuição para a identificação dos principais fatores de degradação em edificações do patrimônio cultural de Porto Alegre", Dissertação de Mestrado em Engenharia Civil - Universidade Federal do Rio Grande do Sul, Porto Alegre.

LIMA, Bruno S. Principais manifestações patológicas em edificações residenciais multifamiliares. 2015. 66 f. Trabalho de conclusão de curso - Curso de Engenharia Civil, Centro de Tecnologia da Universidade Federal de Santa Maria(UFSM), Santa Maria, RS, 2015.

MEDEIROS, Milány K. S.; QUEIROZ, Manoel L. N.; BARRETO Aerson M.; XIII Congresso Internacional sobre patologia e reabilitação de estruturas. In: CINPAR, 13 , 2017, Crato, Ceará. Diagnóstico das manifestações patológicas na Igreja Matriz de Angicos-RN. Crato: 7-9, setembro, 2017, v. 5, pp. 84-100.

MUCl, Netto, Silva; Sistemas de recuperação de fissuras da interface alvenaria de vedação estrutura de concreto: Comparativo entre processos construtivos e análise de custo. Monografia apresentada ao curso de Engenharia Civil da Universidade Federal de Goiás para obtenção do título de Engenheiro Civil, Goiânia,2014.

RODRIGUES, Meandro A.S; SALES, Juscelino C.S. A madeira e suas patologias - Estudo de caso: Igreja Nossa Senhora das Mercês - Itapipoca/CE. Anais do IX Congresso internacional sobre patologia e recuperação de estruturas (CINPAR). p. 1-15. João Pessoa, PB, 2013. Disponível em: http://www.casadagua.com/wpcontent/uploads/2014/02/A1_170.pdf.

VEADO, Fernando R. C. Resgate das técnicas construtivas e a importância dos materiais remanescentes das argamassas utilizadas nas confecções das paredes de barro e dos revestimentos das edificações históricas - Uma abordagem epistêmica. 2008. 210 f. Dissertação (Pós-Graduação em Ambiente Construído e Patrimônio Sustentável) - Escola de Arquitetura da UFMG, Belo Horizonte. 